https://doi.org/10.48009/2_iis_2005_259-265

\title{
TRAINING ISSUES IN INFORMATION TECHNOLOGY: A COMPARISON OF SMALL BUSINESSES AND HOSPITALS
}

\author{
Karen Ketler, Eastern Illinois University, cfkjk@eiu.edu \\ John R. Willems, Eastern Illinois University, cfjrw@eiu.edu \\ Meena Srinivasan, University of Mary Washington, msriniva@umw.edu
}

\begin{abstract}
A comparative study of information systems managers in small businesses and hospitals was performed on the quality and need of training in thirty information technology issues. These thirty issues were categorized into the following four factors: 1) standard applications (such as email), 2) advanced or emerging applications (such as conducting business on the internet), 3) technical issues (such as software availability), and 4) managerial issues (such as data security). The quality of training in emerging applications was rated lowest in both groups while the quality of training in standard applications was rated highest in both groups with hospitals doing comparatively better. The quality of training in all issues were rated poor or below average by both organizations. This research also compares the need of training in both organizations. The researchers computed need of training as the difference between the importance of the issue and the quality of training on the issue. Although hospitals had higher training needs than small businesses on managerial issues, there was remarkable agreement on the need of training in this area in both organizations. This research finds total dissatisfaction expressed by IS managers on the quality and need of training on issues related to information technology. IT training needs to improve in most small organizations and hospitals.
\end{abstract}

Keywords: Information Technology, Training, Small Businesses, Hospitals

\section{INTRODUCTION}

Over the past several years, technology has advanced rapidly and has a profound impact on a variety of business applications in small organizations and hospitals. To maximize the benefits of technology, ongoing quality training programs that make users comfortable with the technology are essential in organizations. Training is critical to productive use of technology, and this is widely known among information systems users and practitioners.

Training is a process of ensuring that the user is prepared with adequate skills to use IT tools. Sein [7] argues that a narrow approach to training is not effective, and is inadequate for training the employees of the future. IT training is a major undertaking, and, like all major projects, it is important to allocate a sufficient budget for training. An appropriate training strategy will be cost effective in the long run when compared to the alternative of a poorly trained workforce. Every organization needs its own unique training strategy for success. Recent decades have seen the demand for technology training increase steadily until it has come to be regarded as a necessary component of doing business [2]. The training objectives of each organization should be met by choosing proper sources of IT training. Organizations that are successful in highly competitive environments understand that technology training is vital, and so adopt continuous training programs to create a culture of learning [3]. 
Nurses, physicians and other medical technician in regional and rural hospitals are currently required to enter patient information in lieu of charting the information. This radical change has daily procedures has required additional training of the medical staff. The current research study was undertaken to determine if, as a result of this reorganization, there are differences between the quality of training and the need for training between hospitals and small business organizations.

The objective of the study reported in this article is to compare hospitals and small business organizations in the quality of training and the need for training in thirty issues in information technology. A review of the literature is presented in the next section. The methodology of the survey is followed by analysis of results and the conclusions from the study.

\section{LITERATURE REVIEW}

Small businesses and hospitals use information technology for increased productivity and performance. Information technology users are expected to have adequate skills in order to achieve these goals. The best decision management can make is to invest in its employees by providing a well-conceived, ongoing, practical training program as software systems are introduced into the business environment as well as when these systems are enhanced with new or increased functionality [3].

Training departments in healthcare institutions are faced with the problem of providing increased services despite reduced budgets. Training in technology has been recognized as important but what is missing is not a lack of understanding of the importance of training, but a lack of funding to support the efforts of providing the training to the users and managers. Although the topmanagement realizes the importance of information technology to the operation of a hospital, there is less support for the information technology area in budgetary allotments [9].

But the problem with poor training is not always related to budget allotments. It is important that there is the right training. The training must give the trainee appropriate knowledge and motivation to use the system [1]. Without a training strategy, it will prove difficult for trainers and organizations to devise an effective program to support end users and meet business objectives, because employers and trainers will only be able to design training programs based on their personal experiences [7].

In a study by Riemenschneider [6], 308 small business executives were interviewed and asked to identify the single most important thing they had learned about managing the use of information technology (IT) in their firms. The most common response was staying current/keeping up with changing IT. The rapid development of technology and the consequent change in working practices require a dramatically different approach towards training and development in organizations than has traditionally been the case. Reaping technology's rewards requires strong top-down leadership that works in tandem with an effective communications plan and comprehensive education programs [5]. 


\section{METHODOLOGY}

\section{Questionnaire}

The two questionnaires used in the surveys of small businesses and hospitals utilized many of the issues included in a telecommunications study by Torkzadeh and Xia [8]. A questionnaire was developed, pilot tested and revised. This questionnaire was revised and utilized in the survey of information systems managers in small businesses. The questionnaire was slightly revised before mailing it out to hospitals. Thus, the questionnaires used in both studies were almost identical. The questionnaire asked the IS managers in both organizations to rate the importance of thirty information technology issues. The responses ranged from "1" indicating no importance to "5" indicating extreme importance. The questionnaire also asked the IS managers to rate the quality of training on these thirty issues. During the pilot test, a five-point Likert scale, ranging from "1" indicating poor training to "5" indicating excellent training was utilized. However, as a result of the input from the pilot testing, a code of "0" indicating no training was added. Thus, a 6-point scale with values from 0 to 5 was used in both the studies. In addition, the survey requested information about the respondents and their organizations. Information included the position, management level, and educational background of the IS manager who responded to the survey as well as the type and the size of their organization.

\section{Subjects}

The names of the organizations included in the survey of small businesses were obtained from the Disclosure Database, which contains financial and management information on over 12,000 public companies. The researchers sent out 1753 surveys to information systems managers in small businesses with sales between $\$ 10$ million and \$40 million. Of these six organizations had a policy of not responding to questionnaires and 336 organizations had changed their names or moved. Of the remaining 1411 surveys, 106 usable forms (7.5\% rate of return) were received.

The second study targeted information systems managers in hospitals. Mailing addresses for 6606 members of the American Hospital Association were obtained through PPS Medical Marketing Group, Inc. (http://www.ppsmed.com). These labels were matched with information derived from the PPS-VI data files published by the Health Care Financing Administration (HCFA). The healthcare organizations were screened to eliminate specialty and long-term care facilities. Teaching hospitals were also excluded since in they often have third-party payers supporting the costs of medical education. As a result of the screening, 2400 surveys were mailed to the IS manager of healthcare organizations. Only two questionnaires were returned as undeliverable. The researchers received 154 usable responses for a $6.4 \%$ rate of return.

One reason for the low rates of return was the fact that both surveys were mailed to the "Information Systems Manager" instead of an individual by name. For both surveys, detailed information on the managers in the organization was not available in the mailing list databases. 


\section{ANALYSIS OF RESULTS}

\section{Demographic Data}

The demographic data provided some unexpected results for small businesses and hospitals. Although the response rate was low, the questionnaire was completed by a relatively high level of management in both surveys. In the survey of small businesses, the average number of employees in the company was roughly 687 . It was found that about $3 \%$ of the small businesses employees were located in the IS department, and approximately $1 \%$ were assigned to the telecommunications or networking area. In the survey of hospitals, the average number of employees in the hospital was nearly 1769 . Only about $2 \%$ of the hospital's employees were located in the information systems department and substantially less than $1 \%$ were assigned to the telecommunications or networking function. The researchers were surprised by how small the information systems and telecommunications/networking functions were in the majority of the small businesses and hospitals. This leads the researchers to conclude that many organizations were outsourcing the majority of the information technology function.

\section{Information Technology Results}

Although the thirty information technology issues are listed in no particular order, it was anticipated from earlier studies that they fell into four groupings: 1) standard applications (such as e-mail), 2) advanced or emerging applications (such as conducting business on the internet), 3) managerial issues (such as data security), and 4) technical issues (such as software availability) [10]. The results from these surveys supported the previous conclusion. Table 1 gives the means of the four groups for both organizations. Refer to Table 2 for the list of the individual issues.

Table 1. Means of the Quality of Training (QOT) and Training Need (TN) by Area

\begin{tabular}{lcccc} 
Area & $\begin{array}{c}\text { QOT } \\
\text { Hospitals }\end{array}$ & $\begin{array}{c}\text { QOT } \\
\text { Small } \\
\text { Businesses }\end{array}$ & $\begin{array}{c}\text { TN } \\
\text { Hospitals }\end{array}$ & $\begin{array}{c}\text { TN } \\
\text { Small } \\
\text { Businesses }\end{array}$ \\
\hline Standard Applications & 2.56 & 2.35 & 1.31 & 1.47 \\
Emerging Applications & 1.65 & 1.65 & 1.60 & 1.38 \\
Technical Issues & 2.02 & 2.15 & 1.72 & 1.42 \\
Managerial Issues & 2.17 & 2.25 & 1.88 & 1.72 \\
0 = no training; 1 = poor training; 3=average training; 5=excellent training & \\
Quality of Training &
\end{tabular}

Information systems managers at small businesses $(\mu=2.35)$ and hospitals $(\mu=2.56)$ rated the quality of training in standard applications higher than other issues. The reasons for this could be due to the numerous sources of training available for standard applications. Unfortunately, the quality of training in the emerging applications area was the lowest rated by both the hospitals ( $\mu$ $=2.02$ ) and the small businesses $(\mu=2.15)$. Many of these issues were related to the internet, such as conducting business on the internet and web page development. This is alarming 
considering the growth of e-healthcare and e-business. It is the emerging applications, which many organizations utilize to get a competitive advantage. It appears that organizations are focusing on short-term goals and are failing to look at long-range plans. It is disappointing that IS managers in both organizations fail to recognize the potential of emerging applications.

Individual issues with the highest quality of training included facsimile devices $(\mu=2.96$ for hospitals and $\mu=2.85$ for small businesses) and e-mail ( $\mu=2.82$ for hospitals and $\mu=2.56$ for small businesses). Even these highest rated issues had a below average rating for the quality of training rating. Video teleconferencing had the lowest quality of training in both organizations $(\mu$ $=1.23$ for hospitals and $\mu=0.86$ for small businesses). Five of the six lowest rated issues were in the emerging issues category for both surveys.

There were many similarities between the hospitals and the small businesses on quality of training on the individual issues. There were only three significant differences. The quality of training on local area networks (LAN) was more highly rated by the IS manager of a small business $(\mu=3.15)$ than the IS manager of a hospital $(\mu=2.42)$. Likewise, the IS manager of a small business $(\mu=2.36)$ was more satisfied by the quality of training in file transfer protocol (FTP) than an IS manager of a hospital $(\mu=1.91)$. Finally, the IS manager of a hospital $(\mu=$ 2.18) was less satisfied with the quality of training on network management and control than the IS manager of a small business $(\mu=2.57)$.

\section{Training Need}

Both organizations have great need for training in all areas, with the highest need in the managerial issues. Training need is computed as the difference between importance and quality of training of an issue. There was remarkable agreement in need of training in managerial issues in both surveys. Complete details are shown in Table 2.

Five out of the eight highest rated issues in need of training were from the managerial issues category for hospitals while six of the eight highest rated issues were from the managerial issues category for small businesses. Managerial issues as data security, data integrity and strategic planning issues had highest need of training in both organizations. Managerial issues are important for the long-term survival and hence more training should be offered on these applications.

There were statistical differences between the hospitals and small businesses on only five of the thirty issues: Hospitals had a greater training need than small businesses on the following four issues: (1) voice data integration; (2) file transfer protocol; (3) data transmission management; and (4) local area networks. Only the need for training on facsimile devices was statistically lower for hospitals than the small businesses. Statistical details are provided in Table 2.

Table 2 compares the quality and need of training in both organizations and contains the group means of the four areas, t-statistics and the probability values of this analysis. 
Table 2. Quality of Training (QOT) \& Need of Training (TN)Small Businesses (SB) and Hospitals (H)

$\begin{array}{lcccccccc}\text { Information Technology Issue } & \text { QOT } & \text { QO } & \text { t } & \text { prob } & \text { TN } & \text { TN } & \text { t stat } & \text { prob } \\ & \text { H } & \text { T } & \text { stat } & & \text { H } & \text { SB } & & \\ & & \text { SB } & & & & & \end{array}$

\begin{tabular}{|c|c|c|c|c|c|c|c|}
\hline \multicolumn{8}{|l|}{ Standard Applications } \\
\hline Voice mail & 2.82 & 2.56 & -1.53 & .1265 & 1.23 & 1.43 & 1.10 .2739 \\
\hline Electronic mail & 2.89 & 2.62 & -1.65 & .1004 & 1.43 & 1.53 & $-0.62 .5389 *$ \\
\hline Voice teleconferencing & 1.95 & 1.75 & -1.15 & .2531 & 1.57 & 1.52 & -0.24 .8117 \\
\hline Facsimile devices & 2.96 & 2.85 & -.14 & .4615 & 0.95 & 1.31 & $2.20 \quad .0288$ \\
\hline Telephony & 2.27 & 1.98 & -1.58 & .1155 & 1.33 & 1.46 & -0.77 .4425 \\
\hline Group Average & 2.56 & 2.35 & -1.78 & .2757 & 1.31 & 1.47 & 1.41 .1607 \\
\hline \multicolumn{8}{|l|}{ Advanced/Emerging Applications } \\
\hline Video teleconferencing & 1.23 & 0.86 & -2.19 & .0292 & 2.03 & 1.79 & -1.25 .2130 \\
\hline Telemarketing & 1.39 & 1.69 & 1.03 & .1034 & 1.15 & 0.98 & -1.00 .3203 \\
\hline Telecommuting & 1.61 & 1.61 & 0.01 & .9930 & 1.73 & 1.42 & - 1.75 .0809 \\
\hline Surfing the Internet & 2.60 & 2.42 & -0.96 & .3378 & 0.93 & 0.71 & -1.21 .2287 \\
\hline Conducting business on the Internet & 1.58 & 1.59 & 0.03 & .9751 & 1.69 & 1.79 & $0.45 .6515^{*}$ \\
\hline Web page development & 1.57 & 1.75 & 0.93 & .3545 & 1.73 & 1.47 & $-1.38 .1701 *$ \\
\hline Group Average & 1.65 & 1.65 & 0.02 & $.9846 *$ & 1.60 & 1.38 & - 1.64 .1034 \\
\hline \multicolumn{8}{|l|}{ Technical Issues } \\
\hline Telecommunications terminology & 1.92 & 2.07 & 0.88 & .3784 & 1.45 & 1.16 & -1.58 .1160 \\
\hline Software availability & 2.03 & 1.99 & -0.20 & .8388 & 1.72 & 1.52 & - 1.10 .2707 \\
\hline Equipment capability & 2.22 & 2.35 & 0.72 & .4699 & 1.70 & 1.47 & -1.14 .2550 \\
\hline Environmental restrictions & 1.79 & 1.73 & -0.28 & .7810 & 1.58 & 1.40 & -1.01 .3129 \\
\hline Vendor Selection & 2.25 & 2.27 & 0.09 & .9258 & 1.42 & 1.32 & -0.56 .5754 \\
\hline Voice/Data integration & 1.66 & 1.86 & 1.13 & .2582 & 2.06 & 1.64 & -2.33 .0209 \\
\hline Electronic Data Interchange (EDI) & 2.13 & 1.91 & -1.14 & .2564 & 1.85 & 1.54 & $-1.69 .0924 *$ \\
\hline Local Area Networks (LAN) & 2.42 & 3.15 & 3.95 & .0001 & 1.81 & 1.12 & $-4.03<.0001$ \\
\hline File Transfer Protocol (FTP) & 1.91 & 2.36 & 2.30 & .0221 & 1.78 & 1.24 & -2.83 .0050 \\
\hline Group Average & 2.02 & 2.15 & 0.83 & .4100 & 1.72 & 1.42 & - $2.07 \quad .0393$ \\
\hline \multicolumn{8}{|l|}{ Managerial Issues } \\
\hline Network management and control & 2.18 & 2.57 & 2.17 & .0309 & 1.93 & 1.66 & -1.51 .1334 \\
\hline Data security & 2.58 & 2.57 & -0.06 & .9537 & 2.09 & 2.07 & -0.12 .9033 \\
\hline Data integrity & 2.22 & 2.30 & 0.44 & .6596 & 2.22 & 2.09 & -0.65 .5189 \\
\hline Strategic planning of telecom & 1.95 & 2.10 & 0.83 & .4079 & 2.15 & 1.85 & $\begin{array}{ll}-1.70 .0912\end{array}$ \\
\hline Managing innovation \& technology & 2.16 & 2.34 & 1.03 & .3049 & 1.80 & 1.69 & $-0.60 \quad .5470$ \\
\hline IT for competitive advantage & 1.76 & 2.04 & 1.63 & .1041 & 1.98 & 1.83 & -0.84 .4000 \\
\hline End user needs & 2.24 & 2.11 & -0.74 & .4592 & 1.47 & 1.41 & -0.33 .7380 \\
\hline Data transmission management & 2.01 & 2.33 & 1.69 & .0928 & 1.81 & 1.36 & -2.46 .0147 \\
\hline Use of PC for telecommunications & 2.26 & 2.33 & 0.39 & .7004 & 1.66 & 1.47 & -1.10 .2733 \\
\hline Info management of telecom & 2.32 & 2.31 & -0.06 & .5545 & 1.66 & 1.49 & $-0.90 \quad .3644$ \\
\hline Group Average & 2.17 & 2.25 & 0.80 & .4233 & 1.88 & 1.72 & - 1.19 .2364 \\
\hline
\end{tabular}

unequal variances 


\section{CONCLUSIONS}

It is of great concern to note the rating of quality of training in both surveys. There was remarkable similarity between the hospitals and the small businesses on the need for training.

1. The information systems managers of small businesses and hospitals both expressed a great dissatisfaction in quality of training for all issues. The only issue on which the quality of training was rated as average or above was local area networks by the IS managers of small business.

2. The information systems managers of small businesses and hospitals both stress the need for additional training in all issues with the highest need in managerial issues.

3. The information systems managers of small businesses and hospitals both gave low rating to the quality of training in the emerging applications and higher rating to standard applications.

4. The quality of training in managerial and technical issues were rated below average by both types of organizations.

The IS managers of both small business and hospitals have spoken their needs. To maximize the benefits of technology, in the future, ongoing quality training programs are crucial in organizations without which any organization may never achieve its potential.

\section{REFERENCES}

1. Bostrom, R. P., Olfman, L., \& Sein, M. K. (1990). The importance of learning style in enduser training. MIS Quarterly, 14(1), 101-119.

2. Compeau, D., Olfman, L., Sein, M., \& Webster, J. (1995). End-user training and learning. Communications of the ACM, 38(7), 24(3).

3. Ference, P. (1997). Technology training: Knowledge is power. Health Management Technology, 18(12), 66.

4. Hersher, B. S. (1999). Technology transitions. Healthcare Executive, 14(5), 48-49.

5. Pitman, B. (1994). How to build a learning culture to cope with rapid change. Journal of Systems Management, 45(7), 27.

6. Riemenschneider, C K. \& Mykytyn, P. P. Jr. (2000). What small business executives have learned about managing information technology. Information \& Management, 37(5), 257269.

7. Sein, M. K., Bostrom, R. P. \& Olfman, L.(1999). Rethinking End-User Training Strategy: Applying a Hierarchical Knowledge-Level Model. Journal of End User Computing, 11(1), 32.

8. Torkzadeh, G., and Xia, W. (1992). Managing Telecommunications by Steering Committees. MIS Quarterly, 16(2), 187-199.

9. Willems, J., Ketler, K. and Hampton, V. (2001). The Importance of and Planning for Information Technology in Healthcare. Proceedings of the National Decision Sciences Institute Conference, 2001, 1168-1171.

10. Willems, J.R., Ketler, K. \& Srinivasan M. (2002). The Importance of Telecommunications: A Comparison of the Viewpoints of Information Systems Managers in Small Businesses and Hospitals. Issues in Information Systems, 3, 660-666.

11. Willems, J.R. \& Ketler, K. (1999). The Information Systems Managers' Viewpoint. Industrial Management \& Data Systems, 99 (2), 81-88. 